\title{
Research on Risk Evaluation Index System of Stampede in Stadium-By Taking Tianhe Sports Center as an Example
}

\author{
Shiyi Lai \\ School of Public Administration/Emergency Management, Jinan University, Guangzhou, China \\ Email: 15626495900@163.com
}

How to cite this paper: Lai, S.Y. (2017) Research on Risk Evaluation Index System of Stampede in Stadium-By Taking Tianhe Sports Center as an Example. Open Journal of Social Sciences, 5, 352-369. https://doi.org/10.4236/jss.2017.57022

Received: July 3, 2017

Accepted: July 22, 2017

Published: July 25, 2017

Copyright $\odot 2017$ by author and Scientific Research Publishing Inc. This work is licensed under the Creative Commons Attribution International License (CC BY 4.0).

http://creativecommons.org/licenses/by/4.0/

(c) (i) Open Access

\begin{abstract}
The stampede happened in Shanghai bund in 2014 is wailsome and the "crowded condition" in Guangzhou Lighting Festival in 2012 is still vivid in our mind. As one of the biggest stadiums in China, the number of audience of each ball game in Tianhe Sports Center was more than 40,000 . Is there a potential of large stampede resulted in by so huge crowd gathered? This paper tries to study and clean up the characteristics of disaster-bearing body, disaster-pregnant environment and disaster-causing factors through literatures by virtue of the theory of crisis cause model, establish risk evaluation index by using analytical hierarchy process and further research the potential of large stampede happened in Tianhe Sports Center by taking Tianhe Sports Center as the example and combining with field survey.
\end{abstract}

\section{Keywords}

Stadium, Stampede, Risk Assessment, Hierarchical Analysis, Disaster System

\section{Research Background}

In the last night of 2014, which was the time of new year's eve celebration, crowds got in and out of Chenyi Square were hedged due to excessive accumulation of visitors and citizens in Shanghai Bund. Some people fell down, and the stampede was caused. 36 people were killed and 49 people were injured in that tragedy at last. This stampede reminds me of my personal experience in Guangzhou International Lighting Festival 2 years ago. The opening ceremony of 2012 Guangzhou Lighting Festival was held in Flower City Square, Guangzhou. However, surprisingly, thousands of people flocked to the Flower City Square like Spring Festival transportation, and it was very crowded there. Many netizens said: "People did not go there to watch light, but the people." Southern Network 
reported that, "The site was jammed and nearly out of control. Vehicles were unable to run at least 500 meters away from the Flower City Square because of too many people on the road, and the field security officers were controlling the vehicles to detour. Especially, the side of opera house near the Flower City Square was too crowded and overwhelmed, which was already out of order." "The reporter tried to follow the stream of people from the south of opera house to the north to get the admission ticket. It's only about 100 meters, but the reporter arrived there with more than ten minutes." [1] Under the condition of such a huge flow of people and disordered scene, what a terrible scene when the Flower City Square, the biggest square, is full with people!

Tourist spots, transportation hubs, large shopping malls, stadiums and other crowded places are the weak link of urban public security system, serious casualties and great damage effect will be caused in case of any emergencies. Both the stampede in Shanghai Bund and Guangzhou International Lighting Festival mentioned above happened in crowded place, and most of them are main sites to hold entertainment activities. Once the stampede occurs, the public security will be seriously threatened. Compared with stampede in Shanghai Bund and Guangzhou International Lighting Festival, the stampede in stadium is also characterized with seriousness of casualties and uncertainty of occurrence; simultaneously, the crowd in stadium not only has the flowing status when entering into or exiting from the stadium, but also has the stable gathering state when watching the performance, which often relates with big event with high social sensitivity, and thus can be used as the research paradigm of security problems in big public places. In addition, the stadium is not only the major stronghold of sports competition, but also the important place of large-scale theatrical performance, conference exhibition and political rally, which has many characteristics, such as high density of people, rapid evacuation, great potential danger, complex space and various functions etc. Stampede and other unexpected events of public security are easy to be happened in the stadium during competition, and the gathered crowd will lead to disastrous consequences of damages and casualties, and further bring about extremely bad social negative effects.

I cannot help thinking of the scene that when thousands of people entered into the narrow exit after the competition, is there a big stampede in case a ball game fan fell down? Therefore, this paper tries to take Guangzhou Sports Center as an example.

\section{Theoretical Basis}

\subsection{Basic Definition and Characteristic of Stampede}

\subsubsection{Definition of Stampede}

Stampede means that, during the assembly, especially when the whole ranks moving crowdedly, someone fell down, but the subsequent people who unknown the truth are still walking forward, trampling on the person who fell down and leading to serious fear, jam, increased number of people falling down and further cause accidents of group injuries with vicious spiral [2]. 
By referring to the related literatures and combining with some life experiences, I think the stampede shall indicate those accidents that many people crushed, choked or even trampled to death.

\subsubsection{Characteristic of Stampede}

After referring to the related literatures and combing with the practical situation, some characteristic of stampede were cleaned up as following:

1) Uncertainty of the time and place of stampede

The time and place of stampede is uncertain, i.e., stampede maybe happened in different public places in different time. Even if in the exit and entrance, corridor and staircase of building or even bridge, the stampede is possible to be happened as long as there is a high density of people gathered.

2) Diversified reasons to induce the stampede

Reviewing similar events in recent years, generally, stampede is a secondary result during the evacuation process induced by a certain emergency; most of them happened by crowded people in the exit and entrance of public place; some of them are caused by unexpected uproar of crowd; or even some serious stampede are resulted in without obvious reasons.

3) Obvious abruptness of stampede

Stampede always suddenly break out without any signs in the highest emotion of gathered crowd. Moreover, once the stampede is happened, a lot of people will be involved in a short time (Several seconds to a few minutes), which may even lead to casualties, causing the accident out of control.

4) Large casualty maybe caused by stampede

Generally speaking, stampede is often happened in places where the crowd is highly concentrated and large outdoor social activities with special significance such as holidays, big sporting events, important concerts and big official events etc. After the occurrence of stampede, most of crowed people are often at a loose end, and cannot help getting herd mentality and blind depression, which will cause the accident out of control and further lead to casualties of a large number of people.

5) Large negative effect caused by stampede

As mentioned above, stampede is always happened in holidays, big sporting events, important concerts, large official events or other important outdoor social activities like religious rites in foreign countries, especially some symbolic and eye-catching activities, which can attract the attention of each sector. Successful holding of some activities will definitely bring high reputation and influence to a certain organization or even the undertaken area and city; conversely, the negative effect of serious causalities or some serious omission due to large scale of stampede in this case is equally huge.

\subsection{Main theories}

\section{Disaster System Theory}

Disaster system theory is researched by taking the disaster as a complicate sys- 


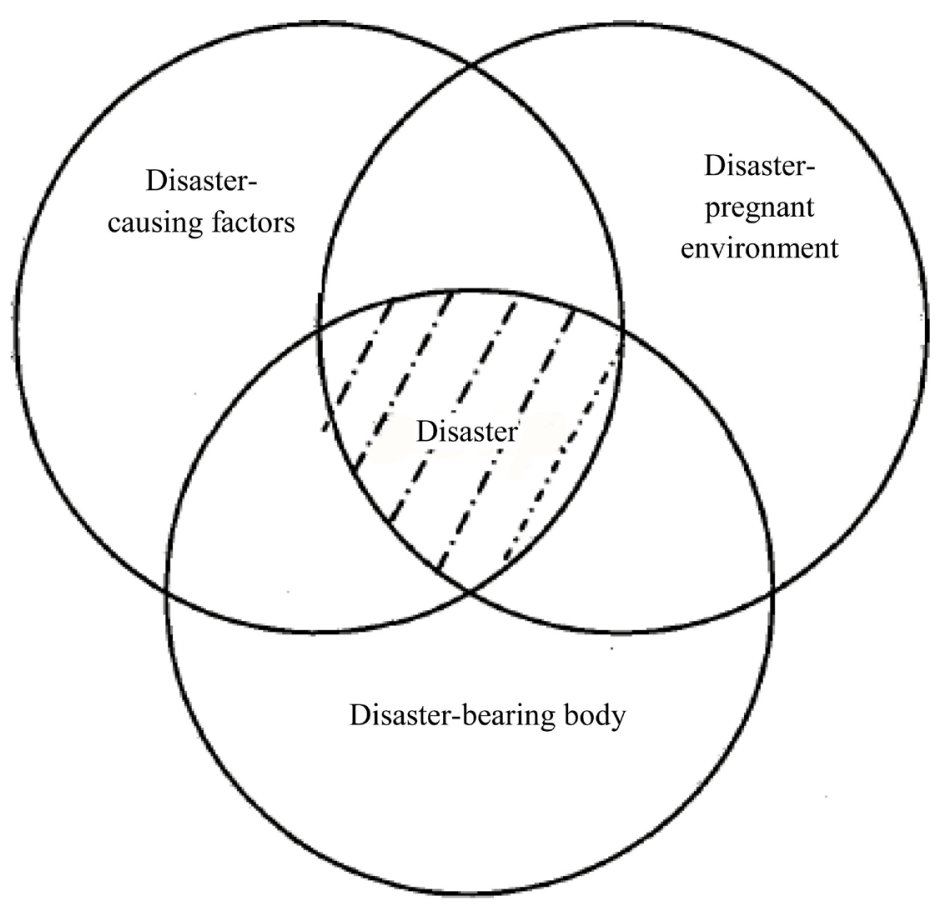

Figure 1. Disaster system theory concept map.

tem resulting from interactions among disaster-causing factor, disaster-pregnant environment and disaster-bearing body, as Figure 1.

The situation of natural disaster is caused by the interaction among disaster-pregnant environment, disaster-causing factors and disaster-bearing body, and its severity is decided by the stability of disaster-pregnant environment, possibility of disaster-causing factors and the vulnerability of disaster-bearing body. The natural disaster system theory was followed in our research, which indicates that, the disaster system is a kind of earth's surface variation system constituted by disaster-pregnant environment, disaster-causing factors and disaster-bearing body.

1) Disaster-causing factor: It refers to variation factor in the natural phenomenon that may lead to the loss of property, casualties, resources, environmental destruction and disordered social system and has a certain negative effect on human society, which is not only the root cause of disaster, but the primary element to form the disaster.

2) Disaster-pregnant environment: It refers to the comprehensive earth's surface environment constituted by the atmosphere, hydrosphere, lithosphere, biosphere and noosphere. The stability of disaster-pregnant environment plays a determinative effect to the formation of disaster-causing factor, mechanism of natural disaster and the final occurrence of disaster, which is directly related to the development trend of natural disaster.

3) Disaster-bearing body: It refers to the object of disaster crisis or the object to bear the impact of disaster, including the fragile substance involving human itself as well as the social and economic environment, which become the disaster-bearing individuals or system affected by disaster because of its insufficient 
capability to withstand shocks under natural disaster. Generally speaking, there will be some damages to the disaster-bearing body. Actually, the disaster-bearing body is the sufferer of natural disaster while the disaster is turned to be transformer of disaster.

\section{Clean up the Reasons Why Big Stampede Is Happened in the Stadium}

In recent years, stampede is frequently happened in stadium. Although the sports games bring happiness and enthusiasm to us, the occurrence of many disasters and disappearance of life also make us thinking and warning at the same time. In 2006, a stampede was happened outside a stadium in the capital city of Philippines, Manila, because crowd rushed into the stadium to take part in a prize game program organized by the Television station; On Feb., $8^{\text {th }}, 2015$, a malicious stampede accident was broken out in a stadium in the capital of Egypt, Cairo. As the security guards used tear gas in trying to stop a large number of fans who tried to force admission, panic was eventually caused and the accident was happened. The occurrence of so many stampedes gives us warning that, we must identify and measure the stampede risk of stadium and make relative assessment and analysis. However, before researching the risk assessment index system of stampede happened in stadium, it is necessary to clean up the causes of big stampede at first. In this paper, the theory of "Crisis factor model" is adopted to analyze the causes of big stampede in stadium, which put the causes of disaster down to the result of interaction between "disaster-bearing body (people and object)", "disaster-pregnant environment(time and space)" and "disaster-causing factor". Combining with stampede, the bearing body is the large scale of crowd. Based on some research literatures related to the stampede, this paper summarizes the possible disaster-pregnant environment and causing factor of big stampede.

Before researching and designing the risk evaluation index system for stampede happened in stadium, it is necessary to clean up the reasons causing big stampede. In the theory of "Crisis cause model", the occurrence of disaster is attributed to the interaction among "disaster-bearing body (human, object)", "disaster-pregnant environment (time and space)" and "disaster-causing factors". Combining with stampede, the bearing body is the massive crowd. According to the related research literatures about stampede, this paper summarizes the possible disaster-pregnant environment and causing factors of large stampede.

\subsection{Characteristics of the Bearing Body of Large Stampede in Stadium}

\subsubsection{The Highly Dense Crowd and Suddenly Accelerated Flow of People} When the density of crowd arriving a certain limit, interaction among people will be caused due to overcrowding, or even lead to pushing and passive movement. Under this circumstance, there is no time for the crowd to respond once anyone falls down, and the stampede will be caused accordingly. When the as- 
sembly activity is terminated in crowded place, the flow of people will be suddenly accelerated, people often rush to enter or exit, so collision is easy to be occurred during such fast flow, and the stampede will be induced because of inertia. In additional, nervous, fear or fierce, enthusiasm status are the causes and performances to result in the disorder of crowd, for example, the celebrating crowd after scoring in important competition, friction is easy to be occurred between crowds, which may become pushing in case of any carelessness and further lead to stampede.

\subsubsection{Improper Management of Crowd}

Improper management of crowd in large group activity may lead to the excessive crowd beyond the capacity of place or high density of people in some places, which will form the major risk to induce stampede. Taking Germany's Duisburg stampede as an example, it was planned that only 200,000 people would participate in the concert, but nearly 1.2 million people came at last, this is the important inducing factor of stampede.

\subsubsection{Abundant and Concentrated Material}

Stadium has characteristics such as temporality, concentration of people and material, abundant activities on the aspect of usage, which may easily induce a fire or riot in case of any carelessness, and further lead to stampede and similar derivative events, causing great politic influence, economic loss and personnel casualties.

\subsection{Characteristics of Disaster-Pregnant Environment of Large Stampede in Stadium}

The place of stampede has obvious uncertainty, which has following characteristics after summarizing according to the research by related scholars:

\subsubsection{Bottle Neck Area}

Bottle neck area is one of high incidence areas of stampede. When the crowd rushes from broad space to the narrow entrance, exit or staircase, except normal flow, many people will push others from the side, hampering the normal flow of people. Arched crowd will be formed at the entrance or exit due to the increasing density of crowd, and then all of them bunch up and cannot pass [3]. At the same time, people will push each other from all directions of arc, and then most of them will be pushed down because of lacking balance suddenly, or even stamped to death by those latecomers eager to get out or obscure the truth. If there is no good evacuation guidance, the entrance and exit will be repeatedly broken into arch and arch collapse.

For example, the entrance, corridor, grandstand, staircase, bridge of public place are important sections of stampede, because human occupation during the design or usage will lead to the narrow scope of passable range, and further form into bottle neck area and become the disaster-pregnant environment of potential stampede. 


\subsubsection{Cross Point}

In case of high density or emergency, people always choose the shortest path to arrive the target place that is the safest place they think. When the moving route of crowd is crossed, people in different directions will conflict and block each other. In serious situations, the two groups of flow move together, they do not make any concessions and form the confrontation with each other, so it is easy to cause mass casualties due to congestion and stampede.

Such as the stampede in Duisburg, Germany, at that time, "Love parade" concert was held in a closed place with only one entrance, people must pass through a underground passage before arriving the entrance, so there were many audiences rush into the site when the activity was coming into the end, while another batch of audience went back home at the same time, in this case, the underground passenger became a cross point, the crowd jammed in the underground passenger and further led to the horrible stampede at last.

\subsubsection{Step or Steep Slope}

Evacuation downward by relying on step or steep slope is easy for people to miss a step or fell down from the slope in case of any disastrous situations, because everyone in the site want to leave and rush to crowd down. Then the subsequent audiences cannot strive forward positively due to heavy pressure of human traffic, and step on the victims who fell down. It is inevitable to avoid the malignant casualties in such fatal situation like "Domino" falling and trampling.

\subsubsection{Wet Road}

In case the rain, snow accumulated on the road after the raining and snowing or oil caused by accident are not cleared immediately, the road friction will be greatly decreased, and the possibility of slipping will be increased. When the crowd density is too large, people who fell down are difficult to stand up, but the subsequent people don't know the situation and they move forward continuously. In this case, the stampede is happened.

\subsubsection{Inadequate Exit of Stadium}

After the football game, people always hope to leave the stadium as soon as possible especially the main team they supported losing scores, they gather to the exit continually, leading to excessive density of crowd around the exit. During the gathering process, the internal pressure is still big, which may damage the organisms of audience or even lead to death from suffocation. Simultaneously, under such high density condition, crowding and stampede are easier to be happened in case of any accident, for instance: audiences escaped in all directions induced by rumor etc.

\subsection{Characteristics of Disaster-Causing Factors for Large Stampede in Stadium}

\subsubsection{Rumor Spread among the Crowd}

Rumor is one of main factors to cause stampede, which mainly spread false and horrible news to induce people's psychological panic, causing people run in all 
directions to avoid the danger. However, such irrational behavior leads to the stampede at last.

For example, on Aug., $31^{\text {st }}, 2005$, stampede was happened in a bridge crossed the Tigris river in the capital of Iraq, Baghdad, causing 1005 deaths at least. Rumor has it that the stampede tragedy is caused by the panic because of a suicide bombers mixing into the crowd. Thus it can be seen that, the spread of rumors in the crowd is the important disaster-causing factor of stampede. Although this event was not happened in stadium, based on the characteristics of high density in stadium, the disastrous consequence induced by the panic of crowd because of rumors will be unimaginable.

\subsubsection{Improper Transfer of Field Management Information}

Under the special circumstances in large activity, information obstacle among the crowd if the managers did not deliver the information in time or delivered wrong or incomplete information is one of the reasons to induce stampede.

In Moscow Massacre occurred on Oct., $20^{\text {th }}, 1982$, as the weather at that time was very cold, there were a few fans came to see the game, only 10,000 tickets were sold in the stadium with an accommodation of 100,000 people. In order to save trouble, all the audiences were concentrated into the stand of area $\mathrm{C}$, but the staffs in stadium seriously breached the security rules of stadium, they only opened one exit of the stand of area $\mathrm{C}$, but locked other entries and exits, causing pushing among fans and serious stampede when they leaving the stadium, resulting in more than 340 persons in danger at last.

\subsubsection{Unexpected Natural Disaster}

In case natural disasters such as rainstorm and typhoon are unexpectedly happened when the crowd is ready to disperse, the crowd may rushes to avoid the natural disaster, and further result in the stampede. At the same time, people may easily fall down on the wet and slippery road due to rainwater, which cause the stampede during the following process of evacuation.

In 1988, the sudden drop of hail swept over the audience in the stadium in Kathmandu, Nepal, but the excavation door was closed tightly, what's more, audiences were not allowed to get close to the door, finally, more than 100 people were killed by pushing and stampede.

\subsubsection{Unexpected Accident}

Unexpected accident mainly refers to those accidents happened in the field of stadium or around the stadium, such as, unexpected explosion and disturbance. The reason why it is one of the factors is that, people often show panic and fright on the aspect of psychology in the front of unexpected accident, and they are eager to leave the field, which may cause the scene more disordered and further lead to the tragedy at last.

On May $9^{\text {th }}, 2001$, fans rioted in the national stadium in the capital of Ghana, Accra, and then the policemen threw tear gas to the riot fans, causing panic, people running in all directions and further leading to stampede and 126 deaths 
finally.

\subsubsection{Unexpected Damage of Public Building}

Under the crowded circumstance, unexpected damage of building inside stadium such as, guardrail broken, building facility collapsed etc., may lead to fire disaster, collapse and other accidents. These factors can not only cause the instability of crowd and stampede, but also expand the loss of damage by stampede accident as a secondary disaster.

In May, 1985, the annual cup of British Football Association was held in Bradford stadium in Scotland, the un-extinguished cigarette led to a fire of wooden stand, causing 56 causalities and more than 200 injured.

\section{Establishment of Risk Evaluation Index System for Stampede in the Stadium}

\subsection{Analytic Hierarchy Process-The Method to Establish Rick Evaluation Index System}

\subsubsection{Analytic Hierarchy Process}

In 1970s, the famous American operational research expert T.L. Satty put forward the analytic hierarchy process (referred to as AHP), which was a multi criteria decision making method combining with qualitative and quantitative analysis.

This method is very useful and effective to deal with complicated decision problem, which is rapidly promoted all over the world. Analytic hierarchy process firstly gives a deep research on the essence, influence factor and internal relationship of problem, and then establishes a hierarchical structure model to achieve the mathematicization of the thinking process of decision, which is a simple method to solve multi-target, multi-criteria or multi-structural complicated decision problems.

\subsubsection{Index System Establishment Process}

The weight determined by analytic hierarchy process is generally classified into five steps as following:

Step 1: Establish the hierarchical analysis model

First, it is necessary to serialize and methodize the complicated problem, disintegrate them into different component factors and then disintegrate those factors into elements (or indexes) at different levels to establish hierarchical structure.

Step 2: Establish the judgment matrix

Compare the index of each hierarchy in analytic hierarchy process model in pairs, and then make judgment of its relative importance by introducing the appropriate scale to form the judgment matrix. 1 - 9 scaling method is generally adopted by analytic hierarchy process, which can scale the importance of each index.

Step 3: Single hierarchical arrangement

The so-called single hierarchical arrangement means the relative importance 
arrangement of a certain hierarchical factor relative to factor of last hierarchy. After the judgment matrix is determined after comparing the importance of each index in pairs, the maximum characteristic root and its corresponding characteristic vector of the judgment matrix can be got through calculation. However, the characteristic vector needs normalization, and each sub-vector of characteristic vector calculated is the weight of each factor and its index.

\section{Step 4: Consistency test}

In order to calculate the rational conclusion by analytic hierarchy process, some consistency tests shall be carried out, and the consistency judged out is the reflection of reliability of two scales of the evaluation index.

\subsection{Risk Evaluation Index Structure Design for Stampede in Stadium}

This paper starts from the theory of disaster system, cleans up the content above and concludes the characteristics of disaster-bearing body, disaster-causing factors and disaster-pregnant environment in stadium, and then designs the risk evaluation index structure based on those characteristics. The detailed index structure model is given as Figure 2:

Relate instruction of secondary index:

B1 Risk of high density of crowd: refers to stampede risk caused by high density of crowd in the stadium.

B2 Risk of accelerated flow of crowd: refers to stampede risk caused by unex-

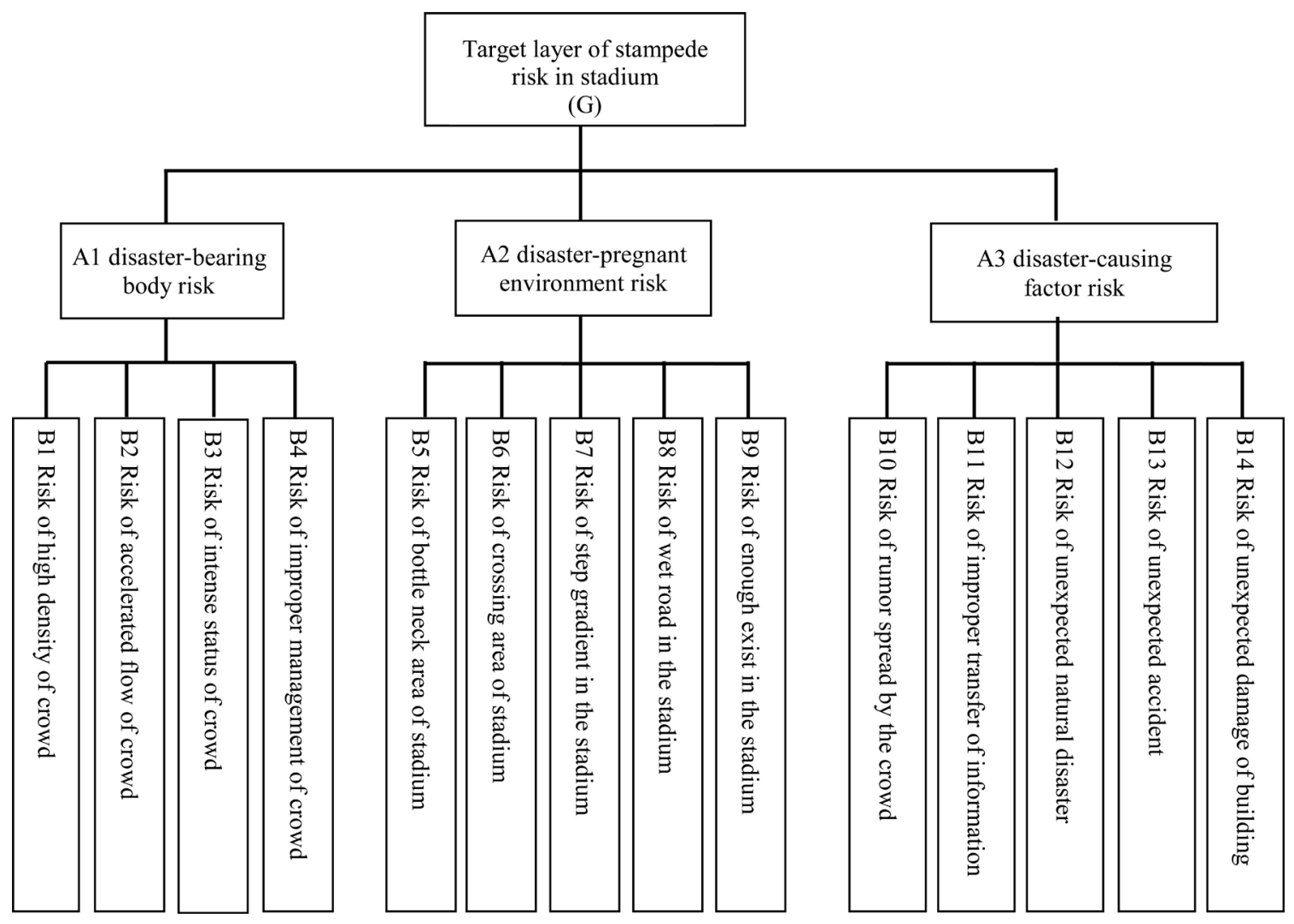

Figure 2. Risk evaluation structure model. 
pectedly accelerated flow of crowd when entering into the stadium before game or exiting from the stadium after game.

B3 Risk of intense status of crowd: refers to stampede risk caused by the friction or even pushing among people due to excessive exciting or angry status of crowd that is different from the normal exciting or regretful status must be have for general game.

B4 Risk of improper management of crowd: refers to stampede risk caused by individual negligence of security staff who managing the crowd or improper coordination of confliction among the crowd.

B5 Risk of bottle neck area of stadium: refers to stampede risk caused by the difficulty of crowd to move forward normally due to the bottle neck area in the stadium.

B6 Risk of crossing area of stadium: refers to stampede risk caused by the insufficient flowing space of internal building in the cross area of crowd flow.

B7 Risk of step gradient in the stadium: refers to stampede risk caused by falling of crowd due to too many and close steps or too steep slope in the stand of stadium

B8 Risk of wet road in the stadium: refers to stampede risk caused by too wet road for the crowd walking in rainy day as it is in the open air.

B9 Risk of enough exits in the stadium: refers to stampede risk caused by the crowd stuck in the exit of stadium before and after the game as there is no enough exit in the building of stadium.

B10 Risk of rumor spread by the crowd: refers to stampede risk caused by non-normal movement of crowd as someone spread rumor among the crowd.

B11 Risk of improper transfer of information: refers to stampede risk caused by non-rational gathering of crowd due to wrong or improper transfer of crowd flow information broadcasted in the field of stadium.

B12 Risk of unexpected natural disaster: refers to stampede risk caused by and fear of crowd and excessive gathering due to unexpected rainstorm, thunderstorm and other weather conditions.

B13 Risk of unexpected accident: refers to stampede risk caused by people's worry about leaving the field due to unexpected fire disaster, explosion and other accidents in and around the site of stadium.

B14 Risk of unexpected damage of building: refers to stampede risk caused by unstable crowd due to unexpected damage of broken guardrail of buildings in the stadium.

\subsection{Risk Evaluation Index System Design of Stampede Happened in the Stadium}

After finishing the risk evaluation index structure model design of stampede happened in the stadium, the judgment matrix was gradually established by referring to the research achievement in the related field, combining with actual experience to watch football game in daily times and comparing the importance of system index in pairs. 
4.3.1. Establish a Judgment Matrix with Two Layers of Index as Shown from Tables 1-4

Table 1. Judgment matrix of first grade index.

\begin{tabular}{cccc}
\hline Index & A1 & A2 & A3 \\
\hline A1 & 1 & $1 / 2$ & $1 / 3$ \\
A2 & 2 & 1 & $1 / 2$ \\
A3 & 3 & 2 & 1 \\
\hline
\end{tabular}

Table 2. Judgment matrix of disaster-bearing body A1 in secondary grade index.

\begin{tabular}{ccccc}
\hline Index & B1 & B2 & B3 & B4 \\
\hline B1 & 1 & $1 / 3$ & $1 / 2$ & 2 \\
B2 & 3 & 1 & 2 & 4 \\
B3 & 2 & $1 / 2$ & 1 & 2 \\
B4 & $1 / 2$ & $1 / 4$ & $1 / 2$ & 1 \\
\hline
\end{tabular}

Table 3. Judgment matrix of disaster-pregnant environment A2 in secondary grade index.

\begin{tabular}{cccccc}
\hline Index & B5 & B6 & B7 & B8 & B9 \\
\hline B5 & 1 & $1 / 2$ & $1 / 3$ & 2 & $1 / 3$ \\
B6 & 2 & 1 & $1 / 2$ & 2 & $1 / 2$ \\
B7 & 3 & 2 & 1 & 3 & $1 / 2$ \\
B8 & $1 / 2$ & $1 / 2$ & $1 / 3$ & 1 & $1 / 3$ \\
B9 & 3 & 2 & 2 & 3 & 1 \\
\hline
\end{tabular}

Table 4. Judgment matrix of disaster-causing factor A3 in secondary grade index.

\begin{tabular}{cccccc}
\hline Index & B10 & B11 & B12 & B13 & B14 \\
\hline B10 & 1 & $1 / 2$ & 2 & $1 / 2$ & 4 \\
B11 & 2 & 1 & 3 & $1 / 2$ & 3 \\
B12 & $1 / 2$ & $1 / 3$ & 1 & $1 / 3$ & $1 / 2$ \\
B13 & 2 & 2 & 3 & 1 & 3 \\
B14 & $1 / 4$ & $1 / 3$ & 2 & $1 / 3$ & 1 \\
\hline
\end{tabular}

\subsubsection{Hierarchy Arrangement and Its Consistency Test} as Shown from Tables 5-8

Table 5. Characteristic vector, comprehensive arrangement and consistency test of first grade index.

\begin{tabular}{ccccccc}
\hline Index & A1 & A2 & A3 & $\begin{array}{c}\text { Characteristic } \\
\text { vector }\end{array}$ & $\begin{array}{c}\text { Comprehensive } \\
\text { arrangement }\end{array}$ & Consistency test \\
\hline A1 & 1 & $1 / 2$ & $1 / 3$ & 0.1638 & 3 & Imax $=3.0112$ \\
A2 & 2 & 1 & $1 / 2$ & 0.2973 & 2 & CI $=0.0056 ; \mathrm{RI}=0.58$ \\
A3 & 3 & 2 & 1 & 0.5389 & 1 & $\mathrm{CR}=0.0096<0.10$ \\
\hline
\end{tabular}


Table 6. Characteristic vector of disaster-bearing body A1, comprehensive arrangement and consistency test of secondary grade index.

\begin{tabular}{cccccccc}
\hline Index & B1 & B2 & B3 & B4 & $\begin{array}{c}\text { Characteristic } \\
\text { vector }\end{array}$ & $\begin{array}{c}\text { Comprehensive } \\
\text { arrangement }\end{array}$ & Consistency test \\
\hline B1 & 1 & $1 / 3$ & $1 / 2$ & 2 & 0.1652 & 3 & Imax $=4.0508$ \\
B2 & 3 & 1 & 2 & 4 & 0.4715 & 1 & CI $=0.01692 ; \mathrm{RI}=0.9$ \\
B3 & 2 & $1 / 2$ & 1 & 2 & 0.2550 & 2 & CR $=0.0188<0.10$ \\
B4 & $1 / 2$ & $1 / 4$ & $1 / 2$ & 1 & 0.1083 & 4 & \\
\hline
\end{tabular}

Table 7. Characteristic vector of disaster-pregnant environment A2, comprehensive arrangement and consistency test of secondary index.

\begin{tabular}{ccccccccc}
\hline Index & B5 & B6 & B7 & B8 & B9 & $\begin{array}{c}\text { Characteristic } \\
\text { vector }\end{array}$ & $\begin{array}{c}\text { Comprehensive } \\
\text { arrangement }\end{array}$ & Consistency test \\
\hline B5 & 1 & $1 / 2$ & $1 / 3$ & 2 & $1 / 3$ & 0.1151 & 4 & Imax $=5.1553$ \\
B6 & 2 & 1 & $1 / 2$ & 2 & $1 / 2$ & 0.1733 & 3 & CI $=0.0388 ; \mathrm{RI}=1.12$ \\
B7 & 3 & 2 & 1 & 3 & $1 / 2$ & 0.2699 & 2 & CR $=0.0347<0.10$ \\
B8 & $1 / 2$ & $1 / 2$ & $1 / 3$ & 1 & $1 / 3$ & 0.0864 & 5 & \\
B9 & 3 & 2 & 2 & 3 & 1 & 0.3553 & 1 & \\
\hline
\end{tabular}

Table 8. Characteristic vector of disaster-causing factor A3, comprehensive arrangement and consistency test of secondary index.

\begin{tabular}{ccccccccc}
\hline Index & B10 & B11 & B12 & B13 & B14 & $\begin{array}{c}\text { Characteristic } \\
\text { vector }\end{array}$ & $\begin{array}{c}\text { Comprehensive } \\
\text { arrangement }\end{array}$ & Consistency test \\
\hline B10 & 1 & $1 / 2$ & 2 & $1 / 2$ & 4 & 0.2022 & 3 & Imax $=5.3072$ \\
B11 & 2 & 1 & 3 & $1 / 2$ & 3 & 0.2618 & 2 & $\mathrm{CI}=0.0768 \mathrm{RI}=1.12$ \\
$\mathrm{~B} 12$ & $1 / 2$ & $1 / 3$ & 1 & $1 / 3$ & $1 / 2$ & 0.0853 & 5 & $\mathrm{CR}=0.0686<0.10$ \\
$\mathrm{~B} 13$ & 2 & 2 & 3 & 1 & 3 & 0.3473 & 1 & \\
$\mathrm{~B} 14$ & $1 / 4$ & $1 / 3$ & 2 & $1 / 3$ & 1 & 0.1034 & 4 & \\
\hline
\end{tabular}

\subsubsection{Conclusion and Comment}

In summary, the risk evaluation index system for stampede happened in the stadium is given as Table 9.

First, the weight of three first grade indexes in the risk evaluation index system of stampede is analyzed, and the weight coefficient of disaster-causing factor risk is the biggest, which is up to 0.5390 ; The weight coefficient of disasterpregnant environment risk is 0.2973 , while the smallest one is disaster-bearing body risk, which is only 0.1638 . This risk weight coefficient indicates that, based on the disaster system theory, the risk of disaster-causing factor is most likely to lead to stampede in the whole stadium, i.e., potential risk to cause disaster, which followed by the effect of disaster-bearing body structure in stadium. All of these remind people of paying attention to the control of risk on the aspect of potential risk to cause disaster and risk of building structure in the stadium during the risk control of stampede in stadium. 
Table 9. Risk evaluation index system for stampede happened in the stadium.

\begin{tabular}{|c|c|c|}
\hline Target hierarchy & First grade index & Second grade index \\
\hline \multirow{14}{*}{$\begin{array}{l}\text { Stampede risk } \\
\text { happened in } \\
\text { stadium }\end{array}$} & \multirow{4}{*}{$\begin{array}{l}\text { A1 Disaster-bearing } \\
\text { body risk }(0.1638)\end{array}$} & B1 Risk of high density of crowd (0.1653) \\
\hline & & B2 Risk of accelerated flow of crowd (0.4715) \\
\hline & & B3 Risk of intense status of crowd $(0.2550)$ \\
\hline & & B4 Risk of improper management of crowd (0.1083) \\
\hline & \multirow{5}{*}{$\begin{array}{c}\text { A2 Disaster-pregnant } \\
\text { environment risk (0.2973) }\end{array}$} & B5 Risk of bottle neck area of stadium $(0.1151)$ \\
\hline & & B6 Risk of crossing area of stadium (0.1733) \\
\hline & & B7 Risk of step gradient in the stadium (0.2699) \\
\hline & & B8 Risk of wet road in the stadium (0.0864) \\
\hline & & B9 Risk of enough exits in the stadium $(0.3554)$ \\
\hline & \multirow{5}{*}{$\begin{array}{l}\text { A3 Disaster-causing } \\
\text { factor risk }(0.5390)\end{array}$} & B10 Risk of rumor spread by the crowd $(0.2022)$ \\
\hline & & B11 Risk of improper transfer of information (0.2618) \\
\hline & & B12 Risk of unexpected natural disaster (0.0853) \\
\hline & & B13 Risk of unexpected accident $(0.3473)$ \\
\hline & & B14 Risk of unexpected damage of building (0.1035) \\
\hline
\end{tabular}

From the perspective of second grade index, the risk weight coefficient of unexpected accident risk (0.3473) and improper transfer of information (0.2618) are biggest in disaster-causing factor risk with biggest risk weight coefficient, the sum of them is more than 0.6 , which indicates that, the key to control the risk source is security personnel's control of the security in stadium and the preparation as well as timely shunting information transfer when the crowd is gathered. Among the second grade index of disaster-pregnant environment risk, the step slope risk (0.2699) and the risk of exit sufficiency in stadium (0.3554) have highest weight coefficient, which indicates that, the appropriate stand slope and sufficient exit of stadium are the key to avoid stampede in stadium. However, the disaster-bearing structure is hard to be repaired or reconstructed due to different kinds of reasons. The most remarkable things among the disaster-bearing body risk indexes with smallest risk weight coefficient are crowd acceleration risk (0.4715) and crowd intense status risk (0.2550), which indicates that, on the one hand, the security department of stadium shall not only closely pay attention to the flow speed of people get in and out of the stadium before and after the game and focus on the counseling and guidance, but also timely grasp the emotion change of crowd in the site. On the other hand, fans need to be patient to watch the game and control their emotions.

\section{Risk Evaluation of Stampede in Stadium-By Taking Tianhe Sports Center as an Example}

By taking Tianhe Sports Center as an example, this paper starts from the key point of risk control mentioned above and carries out the evaluation and analysis of the risk of stampede in stadium by using the risk evaluation index system of stampede in stadium. 


\subsection{Overview of Tianhe Sports Center}

Tianhe Sports Center is located in the central area of Tianhe Sports Center, which was established in 1987. It is a special sports building. Occupying more than 60,000 square meters, Tianhe Sports Center has an oval plastic runway with long axis and short axis of $194 \mathrm{~m}$ and $130 \mathrm{~m}$ respectively, and a standard football field of $105 \mathrm{~m} \times 68 \mathrm{~m}$. Besides, a storm canopy in a length of $210 \mathrm{~m}$ is established for the stand from the east to west. What's more, there are 60,151 seats for audience, and the stadium is equipped with advanced devices [4].

\subsection{Analysis on Disaster-Pregnant Environment in Tianhe Sports Center}

\subsubsection{Lots of Bottle Neck areas in Tianhe Sports Center}

According to my field investigation, there are 24 areas in Tianhe Sports Center, and the number of seats in those 8 middle areas is estimated to be 3850 . For other 12 areas, there are more than 2500 seats on average. In fact, there are only two exits up and down in each area. Based on eye measurement, 15 people can be accommodated side by side in each exit at the same time, so nearly 3000 fans in each area need to exit from those two exits after Evergrande game each time. Thus, a bottle neck area is formed in each exit due to so huge human traffic and relatively narrow exit.

\subsubsection{Many Steps in Tianhe Sports Center}

As a field of football game, in order to help fans to watch the game better, step type slope structure is generally adopted for all the seats in stadium. Tianhe Sports Center has more than 60,000 seats, and all of them are in step type slope structure. So fans in "The top of mountain" need to climb more steps. I have ever sit in "The top of mountain" in area 9, and then I took 5 minutes to find my seat from the entrance, and 10 minutes to get out of the exit from "The top of mountain" due to the great number of fans.

\subsubsection{Tianhe Sports Center Has 24 Exits}

24 areas are classified in Tianhe Sports Center, which are from area 0 to 23. Each area has two exits, which are located in the exit of second floor and tall building, respectively.

\subsection{Analysis on Causing Factor of Tianhe Sports Center}

\subsubsection{Dense Crowd in Tianhe Sports Center under Game Status}

According to some materials, Tianhe Sports Center is able to accommodate more than 60,000 people, and the density is very big. Moreover, the clearance between seats is very narrow, so there is a certain potential condition to cause stampede in Tianhe Sports Center under game status in case of such crowded people and relative compact distribution of seat.

\subsubsection{Sudden Acceleration of the Flow of People at Break and after the Game}

When the referee sounds the whistle at the end of game (break and after the 
game), crowds in different areas of stadium will rush to the exit in very short time, and then the flow of people at exit will be suddenly accelerated, and people often show a tendency to rush in or out, which will lead to friction or even conflict.

\subsubsection{Intense Status of Crowd during the Game}

Football is the first sport in the world. Either wonderful scoring or the ups and downs process of game is concerned by the fans in stadium. I have ever watched all the home games of Evergrande in the whole season last year. The atmosphere of each game was very enthusiastic, and fans were singing, shouting, standing in "human wave" and dancing. The crowd was always in an intense and enthusiasm state during the game; after scoring by Evergrande, the fans cheered to hug with each other for celebration. Therefore, it is easy to cause friction or even pushing among people and further lead to stampede.

\subsubsection{Rainstorm Is Usually Occurred during Games Because of Subtropical Monsoon Climate}

Guangzhou belongs to typical subtropical monsoon climate. It is hot and rainy in summer, and it often rains in the home games of Evergrande in summer. If it suddenly rains in the home game, people often close to the stand with canopy or exit to avoid the heavy rain. In this case, people will be crowded to cause stampede. Simultaneously, as the structure of Tianhe Sports Center looks like a bowl, water is easy to be accumulated in the infield. Besides, the wet road due to rainwater is easy to cause people to fall down, which further leads to the stampede of crowd during the subsequent excavation.

\subsubsection{There Are Hidden Danger of Accident due to Incompact Security and Lots of Decorations in the Stadium}

During each game, fans only need to pass through a regular security inspection (Check for flammable or dangerous liquids or liquids) to enter into the stadium. According to my personal test, someone who hides a lighter or knife in the pocket or wallet and introduces it as mobile phone during the inspection can easily pass the security inspection. Thus it can be seen that, the security inspection in Tianhe Sports Center is very loose, and criminals are able to enter into the stadium with a little more attention. Therefore, there is a potential risk of unexpected accident in Tianhe Sports Center.

What's more, all the audience seats in Tianhe Sports Center are made of plastic, plywood, wooden plate or cotton cloth and other flammable materials, which is able to cause a fire in case of a combustion source. As long as there's a rioting, unexpected fire or other accidents in the site, people will be worried and make the site more disordered or even lead to stampede.

\subsection{Analysis and Suggestion on Stampede in Tianhe Sports Center}

In accordance with "Crisis cause model theory", the formation of all risks is inseparable from the interactions and influences among causing factor, disaster-pregnant environment and disaster-bearing body, and the crisis will be formed only under the cross by three elements. In case the risk causing factor 
has no specified space environment, the surrounding environment will not be damaged at all; if the capability of disaster-bearing body in potential disaster-pregnant environment becomes strong, the crisis will not be formed [5].

Combined with above analyses on disaster-pregnant environment and causing factor in Tianhe Sports Center, we can find that, on the aspect of disaster-bearing body, millions of people become the most natural disaster-bearing body of stampede during each large sports events in Tianhe Sports Center; On the aspect of disaster-pregnant environment, the bottle neck area (in the exit of each area) and step type slope seat structure is the internal structure of stadium, which cannot be changed; On the aspect of causing factor, expect the accident with low rate, no matter the crowd with high density or the acceleration of the flow of people in the entrance and exit after the completion of each game, no matter the intense status of crowd or unexpected rainstorm, these causing factors have higher rate of breaking out. Thus it can be seen, the disaster-bearing body, disaster-pregnant environment and causing factor of stampede in Tianhe Sports Center are easy to be combined together. For example, in case there is a large sport event in Tianhe Sports Center, the huge crowd will become the disaster-bearing body of stampede, and the bottle neck area (exit in each area) is the disaster-pregnant environment. As long as such a causing factor, for instance, a sudden flow of many people happened, the stampede will be easily occurred after the combination of three elements and coordination with trigger point of the completion of game.

However, as the disaster-bearing body, the quality of fans in Guangzhou is generally higher, and most of them are rational and disciplined. No matter the home team, Guangzhou Evergrande, defected the opponent or lose to the visiting team, the emotion of fans is relatively stable when exit from the stadium, and the flow of people is not fast. Simultaneously, it can be seen that, the site of each home game is arranged with lots of garrison strength, 30 policemen are likely to be assigned in each area. What impressed me most is the Asian Football Confederation Champions League, especially when the key opponent is Japanese team (easy to cause fans' national emotion), the related department will form a "human wall" between the home team and visiting team, in order to separate the fans of each time in advance, this is comprehensive on the aspect of risk control for accident. Therefore, when stampede is occurred in Tianhe Sports Center, the capability of disaster-bearing body to resist disaster is very strong, even the causing factor, disaster-pregnant environment and disaster-bearing body of stampede in Tianhe Sports Center is combined together and coordinated with proper trigger point (The home team lose scores in the last moment and the rainstorm is suddenly occurred.), the stampede is likely to be happened. This indicates that, the risk of stampede in Tianhe Sports Center is in the rational control scope. At the same time, on the aspect of resisting stampede, Tianhe Sports Center shall further improve the insufficient information transfer when the crowd leaving the stadium. What's more, crowd control in the area of fans league (especially the leader who has the opinion of fans) as well as the humanis- 
tic management must be concerned simultaneously.

\section{References}

[1] Southern Net, Guangzhou Lighting Festival Organizing Committee Apologized for Improper Organization.

http://gznews.southcn.com/g/2012-12/17/content_60298047.htm

[2] Baidu Baike, Stampede. http://baike.baidu.com/view/4767722.htm

[3] Bai, R. (2009) Research on the Principle of Crowd and Stampede in Large Outdoor Activities. Shenyang Institute of Aeronautical Engineering, Shenyang.

[4] Baidu Baike, Tianhe Sports Center. http://baike.baidu.com/view/579610.htm

[5] Zhu, R.B. (2009) Improvement of Three Elements of Crisis Causes and Crisis Alert Recognition Force. Leading Science, 19, 17.

Submit or recommend next manuscript to SCIRP and we will provide best service for you:

Accepting pre-submission inquiries through Email, Facebook, LinkedIn, Twitter, etc. A wide selection of journals (inclusive of 9 subjects, more than 200 journals)

Providing 24-hour high-quality service

User-friendly online submission system

Fair and swift peer-review system

Efficient typesetting and proofreading procedure

Display of the result of downloads and visits, as well as the number of cited articles

Maximum dissemination of your research work

Submit your manuscript at: http://papersubmission.scirp.org/

Or contact jss@scirp.org 